\title{
Potential benefits and risks of clinical xenotransplantation
}

\author{
This article was published in the following Dove Press journal: \\ Transplant Research and Risk Management \\ 2 July 2012 \\ Number of times this article has been viewed
}

\author{
David KC Cooper' \\ David Ayares ${ }^{2}$ \\ 'Thomas E Starzl Transplantation \\ Institute, University of Pittsburgh \\ Medical Center, Pittsburgh, PA, USA; \\ ${ }^{2}$ Revivicor, Blacksburg, VA, USA
}

\begin{abstract}
The transplantation of organs and cells from pigs into humans could overcome the critical and continuing problem of the lack of availability of deceased human organs and cells for clinical transplantation. Developments in the genetic engineering of pigs have enabled considerable progress to be made in the experimental laboratory in overcoming the immune barriers to successful xenotransplantation. With regard to pig organ xenotransplantation, antibody- and cellmediated rejection have largely been overcome, and the current major barrier is the development of coagulation dysregulation. This is believed to be due to a combination of immune activation of the vascular endothelial cells of the graft and molecular incompatibilities between the pig and primate coagulation-anticoagulation systems. Pigs with new genetic modifications specifically directed to this problem are now becoming available. With regard to less complex tissues, such as islets (for the treatment of diabetes), neuronal cells (for the treatment of Parkinson's disease), and corneas, the remaining barriers are less problematic, and graft survival in nonhuman primate models extends for $>1$ year in all three cases. In planning the initial clinical trials, consideration will be concentrated on the risk-benefit ratio, based to a large extent on the results of preclinical studies in nonhuman primates. If the benefit to the patient is anticipated to be high, eg, insulinindependent control of glycemia, and the potential risks low, eg, minimal risk of transfer of a porcine infectious agent, then a clinical trial would be justified.
\end{abstract}

Keywords: infection, pigs, genetically-engineered, xenotransplantation, islets, xenotransplantation, organs

\section{Introduction}

In the developed world, there is a critical shortage of organs and cells from deceased human donors for the purposes of transplantation. For example, in the US, there are more than 110,000 patients awaiting an organ or cell transplant of one type or another, and yet each year only about 30,000 organs become available from approximately 8000 deceased donors. Despite immense efforts over the past 50 years, we are no closer to resolving the problem of donor organ availability than we were at the beginning of this period. The steadily improving results of allotransplantation have led to an increasing number of patients being put on the waiting list for these procedures.

This problem could be resolved if we were able to use a readily available animal as a source of organs and cells for transplantation into humans. ${ }^{1}$ Indeed, xenotransplantation has several advantages over allotransplantation (Table 1). The pig has been identified as a potential source of organs and cells for this purpose (Table 2 ). ${ }^{2}$ Considerable progress has been made in overcoming the immunological barriers to successful pig organ and cell transplantation in primates, though some barriers remain. ${ }^{3}$
Correspondence: David KC Cooper Thomas E Starzl Transplantation Institute, University of Pittsburgh Medical Center, WI543 Starzl Biomedical Science Tower, 200 Lothrop Street, Pittsburgh, PA I526I, USA

Tel + I 4I2383696|

Fax +| 4I2624 II72

Email cooperdk@upmc.edu 
Table I Major advantages of xenotransplantation over allotransplantation

Unlimited supply of organs, tissues, and cells

Unlimited supply will allow transplantation procedures in 'borderline' candidates who might otherwise be declined

Organs available electively

Avoids the detrimental effects of brain death on donor organs

Provides exogenous infection-free sources of organs, tissues, and cells

Obviates the 'cultural' barriers to deceased human donation present in

some countries, eg, Japan

\section{History of xenotransplantation}

The history of xenotransplantation has been fully reviewed. ${ }^{1,4}$ Xenotransplantation has a long history in the clinic. In the eighteenth century, blood transfusions from animals to humans were attempted, and this practice continued intermittently for 200 years, before it was realized that the results did not warrant the risks. The first corneal xenotransplant was carried out in 1838, more than 65 years before the first corneal allotransplant in $1905 .{ }^{5}$ Organs from nonhuman primates and nonprimate mammals were transplanted in a small number of patients in the early part of the twentieth century, with poor results ${ }^{1}$ (Table 3), although Reemtsma et al reported the survival of one patient with transplanted chimpanzee kidneys who returned to an active life for approximately 9 months until she suddenly died, probably from an acute electrolyte disturbance. ${ }^{6}$ In 1994, Groth and his colleagues carried out the transplantation of fetal porcine islets into patients with diabetes, ${ }^{7}$ though without clinical benefit.

\section{Immune barriers}

\section{Pig organ xenotransplantation}

When a pig organ is transplanted into a nonhuman primate (or into a human), it is followed by hyperacute rejection (Figure 1). This is a consequence of binding of natural antipig antibodies that are present in all humans to antigens on the surface of the pig vascular endothelial cells, activating complement, and causing rapid graft destruction. The most important target for human anti-pig antibodies is the galactose- $\alpha 1,3$-galactose (Gal) antigen, ${ }^{8-10}$ an oligosaccharide very similar in structure to the B blood group antigen. The immunopathology of hyperacute rejection is very similar to that which occurs when organ allotransplantation is carried out across the ABO blood group barrier. ${ }^{11,12}$

If this can be prevented, it is usually followed within days or weeks by acute humoral xenograft rejection (sometimes known as acute vascular rejection or delayed xenograft rejection), which is a slower process, but which is again related to antibody binding, complement activation, and the activity of innate immune cells, such as macrophages and neutrophils. ${ }^{13}$

Hyperacute rejection has largely been overcome by the transplantation of organs from pigs that do not express the important Gal antigens ( $\alpha 1,3$-galactosyltransferase geneknockout pigs), ${ }^{14-16}$ particularly if these also express one or more human complement-regulatory proteins, eg, $C D 46$, CD55, CD59 (Table 4). ${ }^{17-21}$ The major target for anti-pig antibodies is therefore not present, although there is binding of

Table 2 Advantages and disadvantages of the pig as a potential source of organs and cells for humans, in contrast with those of the baboon in this role

\begin{tabular}{lll}
\hline & Pig & Baboon \\
\hline Availability & Unlimited & Limited \\
Breeding potential & Good & Poor \\
Period to reproductive maturity & $4-8$ months & $3-5$ years \\
Length of pregnancy & $114 \pm 2$ days & $173-193$ days \\
Number of offspring & $5-12$ & I-2 \\
Growth & Rapid (adult human size within 6 months)*** & Slow (9 years to reach maximum size) \\
Size of adult organs & Adequate & Inadequate* \\
Cost of maintenance & Significantly lower & High \\
Anatomical similarity to humans & Moderately close & Close \\
Physiological similarity to humans & Moderately close & Close \\
Relationship of immune system to humans & Distant & Close \\
Knowledge of tissue typing & Considerable (in selected herds) & Limited \\
Necessity for blood type compatibility with humans & Probably unimportant & Important \\
Experience with genetic engineering & Considerable & None \\
Risk of transfer of infection (xenozoonosis) & Low & High \\
Availability of specific pathogen-free animals & Yes & Yes \\
Public opinion & More in favor & Mixed \\
\hline
\end{tabular}

Notes: *The size of certain organs, eg, the heart, would be inadequate for transplantation into adult humans; **breeds of miniature swine are approximately $50 \%$ of the weight of domestic pigs at birth and sexual maturity, and reach a maximum weight of approximately $30 \%$ of standard breeds. 
Table 3 Summary of clinical xenotransplantation of organs in the twentieth century

\begin{tabular}{lll}
\hline Donor & $\mathbf{n}$ & Survival \\
\hline Kidney - primate & $(30)$ & $\mathrm{I}$ day -9 months \\
- nonprimate & $(3)$ & $3-9$ days \\
Heart - primate & $(5)$ & $<\mathrm{I}-20$ days \\
- nonprimate & $(4)$ & $<$ I day \\
Liver - primate & $(\mathrm{II})$ & $<\mathrm{I}-70$ days \\
- nonprimate & $(\mathrm{I})$ & $<2$ days \\
\hline
\end{tabular}

Copyright $\odot 2012$ The Royal College of Surgeons of England. Reproduced with permission of Taniguchi $S$ and Cooper DKC (content has been modified in this article). ${ }^{101}$

antibodies to non-Gal antigenic targets, ${ }^{21-23}$ the nature of which is unknown at present ${ }^{24}$ except in one respect (see below). Nevertheless, the effect and extent of complement activation is reduced by the presence of the human complement-regulatory proteins. Acute humoral xenograft rejection can also be greatly inhibited when organs from these pigs are transplanted, but may not be completely prevented as the activity of the innate immune cells continues..$^{13}$ The addition of potent immunosuppressive therapy, particularly including a costimulatory blockade agent, ${ }^{25}$ inhibits acute humoral xenograft rejection further, and graft survival of weeks or months can be achieved. ${ }^{26-31}$

Isolated acute cellular rejection, ie, T cell-mediated rejection, has rarely been seen after pig organ transplantation into nonhuman primates, either because acute humoral xenograft rejection intervenes or because the potent immunosuppressive therapy successfully prevents this response. Graft atherosclerosis (chronic rejection), however, has been documented in hearts that have functioned for longer than approximately 3 months in nonhuman primates (Figure 2). ${ }^{28,30}$

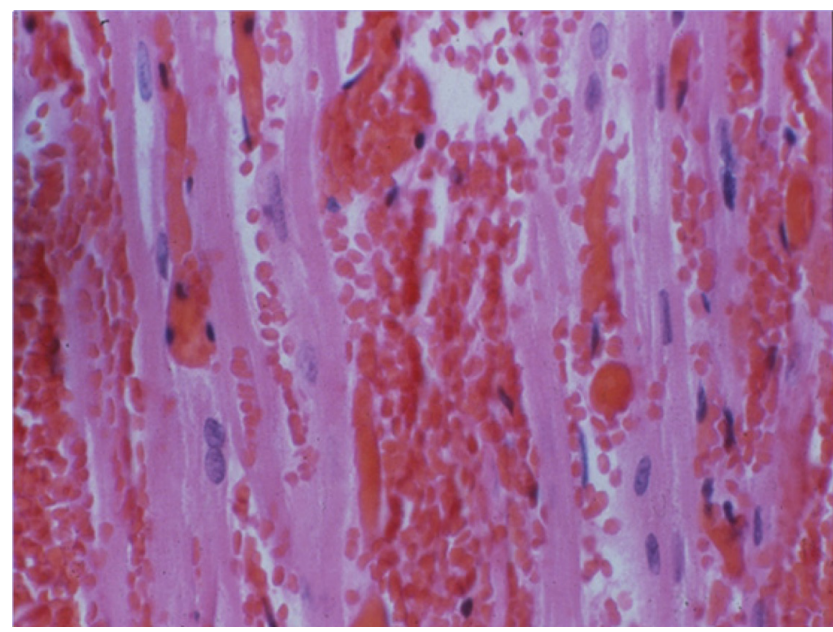

Figure I Hyperacute rejection (defined as occurring within the first 24 hours after transplantation) of a pig heart in a baboon.

Complement-mediated injury associated with the immediate binding of natural antipig antibodies to antigens expressed on the vascular endothelium of the pig organ, eg, Gal $\alpha$ I-3Gal, results in disruption of the myocardial capillaries, with massive interstitial hemorrhage and edema.
Table 4 Genetically modified pigs currently available for xenotransplantation research

\section{Gal antigen deletion or 'masking'}

$\alpha$ I,3-galactosyltransferase gene-knockout (GT-KO)

Human $\mathrm{H}$-transferase gene expression (expression of blood type $\mathrm{O}$ antigen)

Endo-beta-galactosidase $\mathrm{C}$ (reduction of $\mathrm{Gal}$ antigen expression)

Complement regulation by human complement-regulatory gene expression

CD46 (membrane cofactor protein)

CD55 (decay-accelerating factor)

CD59 (protectin or membrane inhibitor of reactive lysis)

Anticoagulation and anti-inflammatory gene expression

or deletion

Human tissue factor pathway inhibitor (TFPI)

Human thrombomodulin

Human CD39 (ectonucleoside triphosphate diphosphohydrolase-I)

von Willebrand factor-deficient (natural mutant)

Suppression of cellular immune response by gene expression or downregulation

Porcine CTLA4-Ig (cytotoxic T-lymphocyte antigen 4 or CDI52)

LEA29Y (inhibition of the B7/CD28 costimulatory pathway of T-cell activation)

CIITA-DN (MHC class II transactivator knockdown, resulting in swine leukocyte antigen class II knockdown)

Human TRAIL (tumor necrosis factor-alpha-related apoptosis-inducing ligand)

HLA-E/human $\beta 2$-microglobulin (inhibits human natural killer cell cytotoxicity)

Human CD47 (for species-specific CD47-SIRP-alpha natural interaction on macrophages)

Human FAS ligand (CD95L)

Human GnT-III ( $\mathrm{N}$-acetylglucosaminyltransferase III)

\section{Antiapoptotic gene expression}

Human A20 (tumor necrosis factor-alpha-induced protein 3)

Human heme oxygenase-I (HO-I)

Human TNFRI-Fc (tumor necrosis factor-alpha receptor I-Fc)

Prevention of porcine endogenous retrovirus (PERV) activation PERV siRNA

Modified from Ekser et $\mathrm{al}^{3}$; pigs with combinations of genetic modification, eg, GT-KO with added transgenes, are available.

In summary, with organs from the current genetically engineered pigs and with potent immunosuppressive therapy, hyperacute rejection can largely be prevented and the onset of acute humoral and acute cellular rejection can be greatly delayed. However, activation of the vascular endothelium of the organ by anti-non-Gal antibodies and possibly innate immune cells results in the initiation of coagulation dysfunction in the graft. This takes the form of the development of a thrombotic microangiopathy in the small vessels of the graft and/or a systemic consumptive coagulopathy that results in spontaneous hemorrhage..$^{30,32,33}$ Activation of recipient platelets by the presence of the graft endothelium occurs and is an initiating factor. ${ }^{34}$ Coagulation dysregulation can be reversed if the graft is excised before hemorrhage develops, 


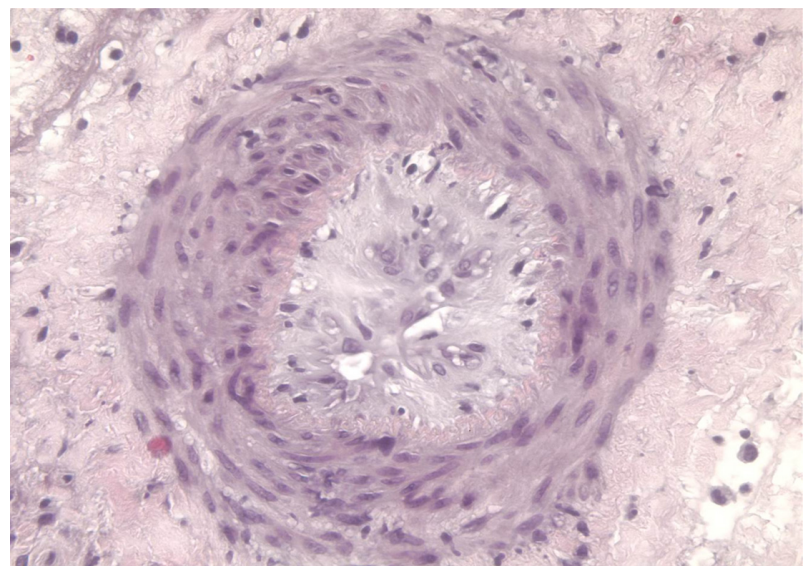

Figure 2 Chronic rejection (graft atherosclerosis) in a vessel in a pig heart transplanted into a baboon 4 months previously (from Kuwaki K, et $\mathrm{al}^{31}$ ). Copyright (c) 2012 John Wiley and Sons. Reproduced with permission of Kuwaki K, Knosalla C, Dor FJ, et al. Suppression of natural and elicited antibodies in pig-tobaboon heart transplantation using a human anti-CDI54 monoclonal antibody-based regimen. Am J Transplant. 2004;4(3):363-372. ${ }^{31}$

indicating that it is the presence of the xenograft that is the initiating factor. ${ }^{32}$

Coagulation dysfunction is almost certainly a combination of immune activation of the porcine vascular endothelium by anti-pig antibodies, complement, and innate immune cells, and the presence of several molecular incompatibilities between pig and primate that lead to a change in endothelial phenotype from anticoagulant to procoagulant. ${ }^{35-40}$ For example, pig thrombomodulin is not an efficient cofactor for thrombin's activation of protein $\mathrm{C}$, and pig von Willibrand factor is associated with excessive primate platelet aggregation.

Despite maximum heparin therapy or the administration of other anticoagulant or antithrombotic agents, thrombotic microangiopathy and consumptive coagulopathy have to date not been prevented. However, new genetic modifications of the organ-source pigs, including expression of an antithrombotic gene, such as thrombomodulin, tissue factor pathway inhibitor, or CD39, may resolve this problem (Table 4). ${ }^{3}$ These pigs are just becoming available for testing in nonhuman primate models.

Thrombotic microangiopathy appears to be the dominant pathology after pig heart xenotransplantation (Figure 3), 28,30,31 whereas consumptive coagulopathy occurs more rapidly after pig kidney xenotransplantation (Figure 4). ${ }^{29,34}$ This difference in outcome may be related to differences in the vascular endothelium of the two organs. ${ }^{41}$ In our own experience, the more rapid development of consumptive coagulopathy results in a reduced period of survival of porcine kidneys in nonhuman primates. Whereas heterotopic heart grafts have functioned for 6-8 months, ${ }^{28,42}$ life-supporting kidney transplants have not functioned for even 3 months. ${ }^{26,29}$ However,

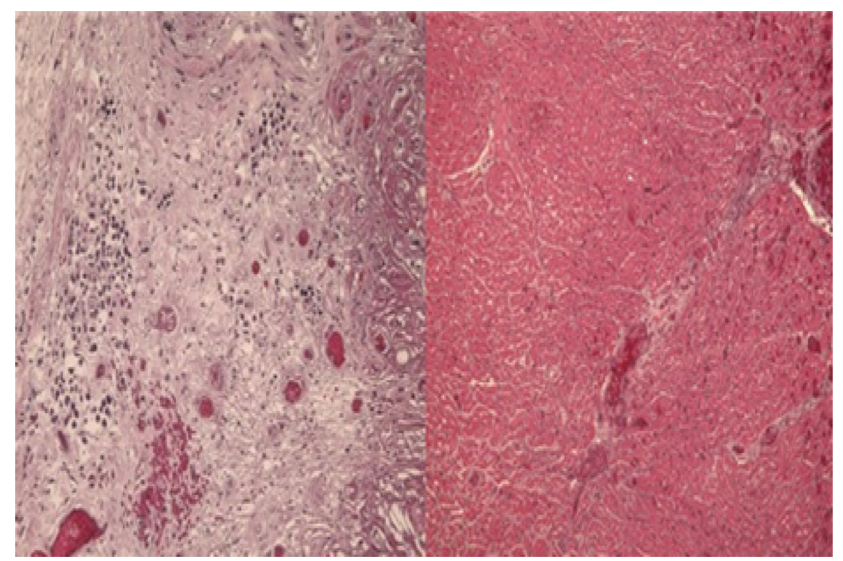

Figure 3 Thrombotic microangiopathy in a pig heart transplanted into a baboon. Fibrin deposition and platelet aggregation results in thrombosis within the vessels of the graft. Minor pathological changes can be seen within a month (right); ischemic fibrosis occurs when the thrombosis becomes extensive (left).

survival of life-supporting orthotopic heart grafts has also had a limited survival of less than 2 months, ${ }^{43,44}$ and so the difference in survival may not be great.

Despite adequate hepatic function, ${ }^{45,46}$ pig liver xenotransplantation in a nonhuman primate is followed by a different form of coagulation dysfunction, namely by an immediate loss of platelets. ${ }^{47}$ The platelets probably sequestrate within the graft or maybe are phagocytosed by cells in the graft. ${ }^{48,49}$ The profound thrombocytopenia results in life-threatening spontaneous hemorrhage into the tissues and from the body orifices within days.

The immune responses and coagulation dysregulation that are associated with pig heart or kidney xenotransplantation are very much accelerated after pig lung xenotransplantation. ${ }^{50,51}$ Survival after pig lung transplantation in a nonhuman primate is therefore currently limited to hours or days.

It is hoped that further planned genetic modifications of the organ-source pigs will overcome most of these barriers (Table 4). The genetic modifications that we believe may be necessary to overcome these various immune and pathophysiological barriers have recently been discussed in relation to xenotransplantation of the lung, in which these problems are particularly acute and vigorous. ${ }^{52}$

There is also a documented systemic inflammatory response to the presence of a pig organ xenograft, ${ }^{53}$ and again this may require genetic modification to the organ-source pig if it is to be prevented or minimized. Expression of thrombomodulin, CD39, heme oxygenase-1, or A20 may prove valuable (Table 4).

\section{Pig cell xenotransplantation}

The barriers associated with transplantation of less complex organs, such as the cornea or cells, eg, pancreatic islets or dopamine-producing neuronal cells, appear to be less 

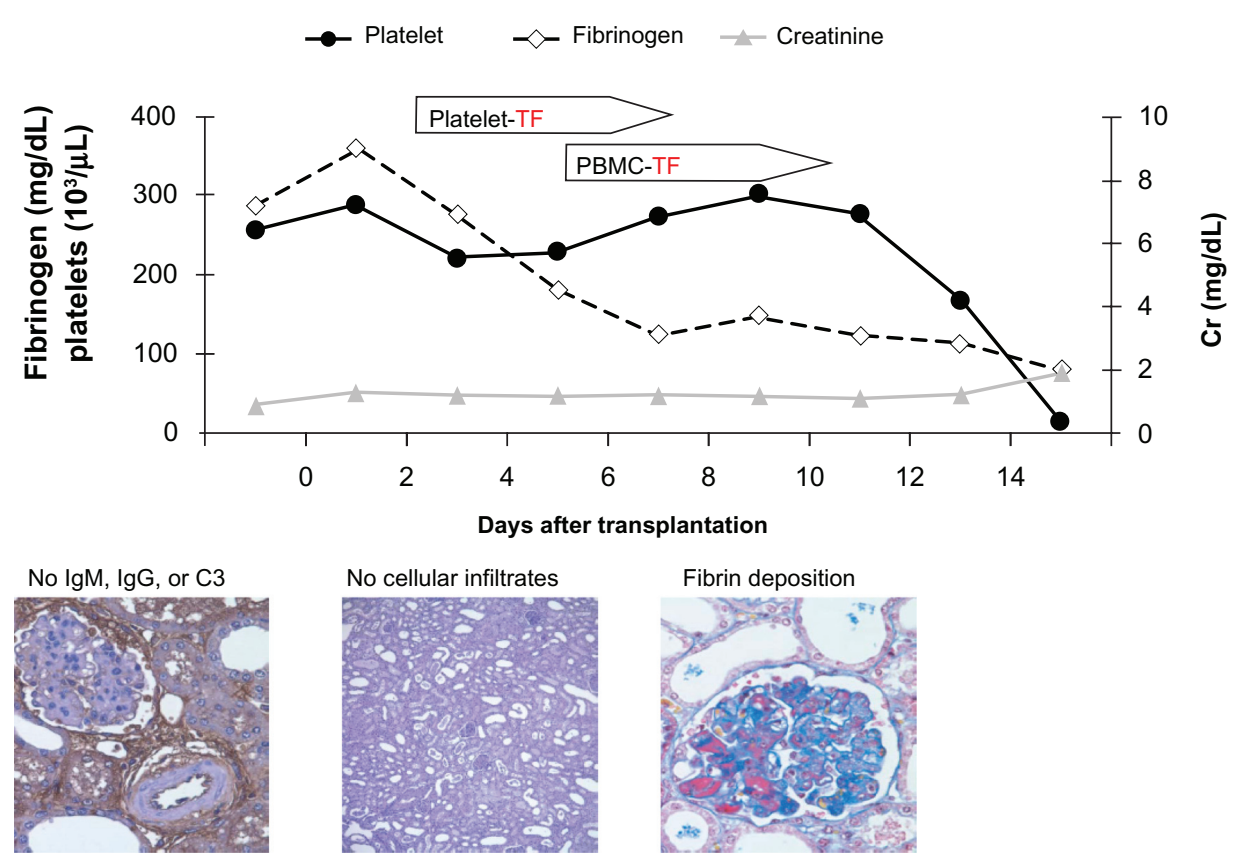

Figure 4 Correlation between platelet count and fibrinogen level (indicating the development of a consumptive coagulopathy) and tissue factor expression on platelets and peripheral blood mononuclear cells (PBMC) in a baboon following GTKO/CD46 pig-to-baboon kidney transplantation.

The baboon was killed with a functioning graft (serum creatinine $2.0 \mathrm{mg} / \mathrm{dL}$ ) on day 16 (top). Microscopic examination of the kidney at necropsy showed no or minimal deposition of IgM, IgG, or C3, no cellular infiltrates, but some deposition of fibrin (bottom) Copyright @ 2012 John Wiley and Sons. Reproduced with permission of Lin CC, Ezzelarab M, Shapiro R, et al. Tissue factor expression on recipient platelets is associated with consumptive coagulopathy in pig-to-primate kidney xenotransplantation. Am J Transplant. 2010;10(7):1556-1568. ${ }^{34}$

Abbreviation: TF, tissue factor.

problematic. With regard to islets and neuronal cells, the absence of a vascular endothelium in these transplants may be a major factor in their better outcome. However, there are still significant problems to be overcome.

With regard to pig islet transplantation, there is an initial loss of islets when they are infused into the portal vein (which is the current approach for islet allotransplantation). An inflammatory response is set up that leads to destruction of a significant percentage of the islets. This event, known as the instant blood-mediated inflammatory reaction (IBMIR) ${ }^{54-59}$ (reviewed in van der Windt et $\mathrm{a}^{160}$ ), is probably a combination of the effect of antibody binding to the grafts with subsequent activation of complement and coagulation and innate immune cells, and a nonspecific effect related to the (unnatural) presence of islets in the blood, which also leads to activation of complement and coagulation. It may therefore have both immune and nonimmune component mechanisms; recent data suggest immune mechanisms are playing a greater role than hitherto thought. ${ }^{61}$ If sufficient islets remain functional, however, long-term ( $>1$ year) correction of diabetes can be achieved as long as potent immunosuppressive therapy is continued; healthy-looking pig islets can be identified in the nonhuman primate liver (Figure 5). ${ }^{62-64} \mathrm{New}$ genetically engineered pigs with multiple gene modifications, some of which are specifically directed to protecting the islets from IBMIR (using an insulin promoter), are now becoming available. ${ }^{3}$
There is some evidence that neonatal pig islets may have some advantages over adult pig islets. ${ }^{65,66}$ Furthermore, in an effort to avoid the substantial loss of islets from IBMIR, efforts are being made to identify suitable sites for islet transplantation other than the portal vein (reviewed in van der Windt et $\mathrm{al}^{167}$ ).

Encouraging results have also been obtained when islets are transplanted within microcapsules that protect them

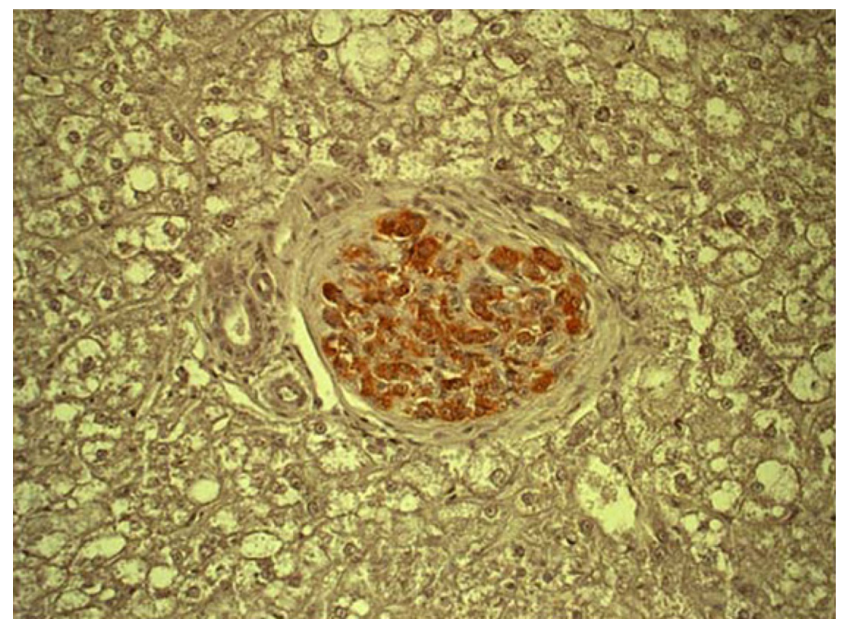

Figure 5 Insulin immunostaining of liver section in a streptozotocin-induced diabetic monkey recipient I year after transplantation of islets from an adult CD46-transgenic pig. Blood glucose levels had remained normal throughout this period without the need for any exogenous insulin therapy Copyright (C) 2012 John Wiley and Sons. Reproduced with permission of van der Windt DJ, Bottino R, Casu A, et al. Longterm controlled normoglycemia in diabetic non-human primates after transplantation with hCD46 transgenic porcine islets. Am J Transplant. 2009;9(12):2716-2726. . 
to some extent from the immune response of the host. In these cases, exogenous immunosuppressive therapy is not required. Survival of more than 6 months has been achieved in nonhuman primates, ${ }^{68,69}$ but it is uncertain whether the graft subsequently fails from ischemia or a slow immune response. The minimal risk to the patient (in the absence of the need for immunosuppressive therapy) has enabled clinical trials to be initiated. ${ }^{70}$

There are several million patients worldwide with neurodegenerative diseases who might benefit from the transplantation of specific neuronal cells. Long-term $(>1$ year) survival of pig neuronal cell xenotransplantation in the treatment of monkeys with an induced Parkinson-like condition has also been achieved by the transplantation of fetal pig dopamine-producing cells that transgenically express CTLA4-Ig, a potent costimulatory blockade molecule. ${ }^{71}$

Although in the Western world the availability of deceased human corneas meets the needs of clinical corneal transplantation, worldwide there is a major deficiency ${ }^{5}$ (Table 5). As the cornea is a relatively avascular structure and therefore less susceptible to antibody binding and complement activation, ${ }^{5}$ wild-type pig corneal xenotransplantation in nonhuman primates has also been associated with relatively long-term graft survival. ${ }^{72,73}$ Importantly, this has been achieved with only local corticosteroid therapy to the eye. The availability of genetically engineered pigs should increase corneal graft survival further.

The potential of red blood cell xenotransfusion from genetically engineered pigs into patients is also being investigated. ${ }^{74,75}$ Red blood cells from genetically modified pigs have been demonstrated to be preferable to ABO-

Table 5 Estimated numbers of corneal allotransplants carried out in 2008 and numbers of patients awaiting corneal transplantation in selected countries*

\begin{tabular}{lll}
\hline Country & $\begin{array}{l}\text { Estimated number } \\
\text { of cases per year }\end{array}$ & Waiting list \\
\hline United States & 41,652 & Minimal \\
United Kingdom & 2711 & 500 \\
South Africa** & 330 & 1884 \\
India & 15,000 & 300,000 \\
China & 101 & $4,000,000$ \\
Taiwan & 263 & 637 \\
Korea & 480 & 3630 \\
Japan & 1634 & 2769 \\
Australia & 1096 & Minimal \\
\hline
\end{tabular}

Notes: From Hara and Cooper ${ }^{5}$; Based on eye bank data in individual countries and personal communications; **in sub-Saharan Africa, the number of corneal transplants carried out annually has been falling for several years because of the high incidence of human immunodeficiency virus positivity in the potential donor population. incompatible allotransfusions, but not yet comparable to ABO-compatible transfusions. As red blood cells do not have nuclei, modifications to the standard techniques of genetic engineering are required before this can be entirely successful. However, it is likely that the pig will eventually become a limitless source of blood for transfusion, particularly in countries where a high incidence of human immunodeficiency virus infection has greatly reduced the availability of human donor blood.

\section{Other immunological considerations}

In addition to Gal, pigs express another known carbohydrate antigen, namely $N$-glycolylneuraminic acid (NeuGc), which is also expressed in all nonhuman primates, but not in humans. ${ }^{76-79}$ Humans are therefore the only mammals that develop natural preformed anti-NeuGc antibodies. The effect of this antigen-antibody binding therefore cannot be tested in nonhuman primate models. Although the effect of the presence of NeuGc antigens is not considered to be as powerful as that of Gal antigens, nevertheless they do provide a target for binding of natural antibodies and for subsequent sensitization that may be problematic, at least in some patients. It is therefore possible that, particularly for organ transplants, pigs that do not express NeuGc may be required.

Other important points for which there is some evidence are that sensitization to human leukocyte antigens would not be detrimental to the outcome of clinical pig organ xenotransplantation ${ }^{80}$ and sensitization to pig antigens after clinical pig organ xenotransplantation would not preclude subsequent allotransplantation. ${ }^{80}$

\section{Physiological aspects of xenotransplantation}

Even if all of the immune barriers and coagulation discrepancies can be overcome, the question remains as to whether the various pig organs will function adequately in a primate environment. There are several differences in anatomy and physiology between pig and primate that may result in lessthan-perfect function. ${ }^{1,81-83}$

However, evidence from experience of pig orthotopic heart transplantation in nonhuman primates, suggests that cardiac function will be adequate. ${ }^{43,44}$ Conclusions with regard to function of transplanted pig kidneys need to be cautious, as proteinuria is almost always present; ${ }^{29,34}$ this may be a result of immune activation or injury, but other pathophysiological causes have not been ruled out. Pig liver function appears to be surprisingly good, but as follow-up has been restricted 
to approximately a week (because of the development of profound thrombocytopenia), definite conclusions cannot be drawn. ${ }^{45-47}$ Pig lung function cannot be adequately assessed, as injury is so rapid. Although there are some differences in glucose metabolism between pigs and primates, ${ }^{84}$ pig islet function in nonhuman primates is clearly adequate if enough islets survive the initial IBMIR. ${ }^{64}$ It should be noted that nonhuman primates have higher insulin requirements than humans and pigs, which makes them a more challenging preclinical model for pig islet xenotransplantation studies. ${ }^{84}$

\section{Clinical trials of xenotransplantation}

Although progress has been slow, encouraging progress has been made during the past 20 years since the initial introduction of genetically engineered pigs and the availability of costimulatory blockade immunosuppressive agents. The longest survivals of organs and cells in preclinical models now extend to approximately 8 and greater than 12 months, respectively (Table 6).

\section{Risk-benefit ratio}

It will be important to confirm these encouraging results in clinical trials, and considerable thought has been given to the basis on which these trials can be justified. In particular, there has been careful consideration of what results would be required to warrant clinical trials of pig heart ${ }^{85}$ and pig islet xenotransplantation. ${ }^{86}$ Furthermore, the 'ideal' patients who might be considered for these initial trials are being carefully considered..$^{85,87,88}$

The ethics of performing clinical trials are largely based on a calculation of the risk-benefit ratio of the procedure, particularly with regard to the potential risk of exposing the patient and possibly members of the community to a porcine infection (see below). ${ }^{89-91}$

Table 6 Approximate maximum periods of survival of pig organs and cells in nonhuman primates (without retransplantation)

\begin{tabular}{ll}
\hline Organ/cells & $\begin{array}{l}\text { Period of graft or } \\
\text { recipient survival }\end{array}$ \\
\hline Neuronal cells & $>$ I year \\
Free pancreatic islets & $>$ year \\
Cornea & $>$ I year \\
Microencapsulated pancreatic islets & $>8$ months \\
Hepatocytes & $>8$ months \\
Heterotopic (non-life-supporting) heart & $<8$ months \\
Life-supporting kidney & $<3$ months \\
Orthotopic (life-supporting) heart & $<2$ months \\
Life-supporting liver & 9 days \\
Life-supporting lung & 5 days \\
\hline
\end{tabular}

Thought is therefore being given to clinical trials of cell or corneal xenotransplantation, where survival of the graft is anticipated to be likely and the risks minimal, rather than to clinical trials or organ xenotransplantation, where at present the benefits cannot be guaranteed and the risks are certainly greater.

For example, there are several million patients worldwide who could benefit from a corneal transplant, ${ }^{5}$ but human corneas are not available to them. The risks associated with pig corneal xenotransplantation are considered to be low; if a pig corneal graft should fail, the patient would remain with corneal blindness, but it is unlikely there will be any life-threatening complications from this procedure. Again, if pig islet transplants are carried out, particularly if they are encapsulated and therefore no immunosuppressive therapy is required, the risks are likely to be few. Failure of the graft would necessitate the patient returning to daily insulin therapy, but other complications are unlikely to be seen, at least based on our experience in nonhuman primates. It is therefore highly likely that corneal, islet, or neuronal cell transplants will be the first to enter clinical trials. Indeed, under the supervision of the Department of Health in New Zealand, there is a clinical trial being undertaken at present of encapsulated porcine islets in patients with diabetes. ${ }^{70}$

With regard to organ transplants, however, the current risks are significantly higher. The development of a consumptive coagulopathy could, of course, be life-threatening. Even in the presence of good graft function, a risk of consumptive coagulopathy would contraindicate a clinical trial. The only possible exception to this would be if the organ were transplanted for a limited period of time as a bridge to allotransplantation. For example, a patient with fulminant hepatitis may die within 48-72 hours after admission to hospital. If he/she could be maintained by an orthotopically transplantated pig liver for this period while a human liver was obtained, this might well be life-saving. ${ }^{92}$ A clinical trial may therefore be justified if preclinical work indicates that a pig liver will function consistently without major complication for periods of greater than 1 week. At present (as mentioned above), this is not the case, as transplantation of a pig liver into a baboon is followed by an almost immediate thrombocytopenia, which could prove lifethreatening, particularly if allotransplantation were attempted in the relative absence of platelets. ${ }^{47}$

\section{The potential risk of transfer of pig microorganisms}

The other major consideration with regard to potential complications from clinical xenotransplantation relates 
to the potential risk of the transfer of a porcine virus, microorganism, or parasite with the donor organ into the recipient and, possibly of greater importance, from the recipient to the general population. ${ }^{93}$ Risk of such an infectious complication will be minimized by barrier housing of the organ-source pigs and by monitoring for the presence of infectious organisms at intervals before the organs or cells are recovered for transplantation. It would seem that the majority of potentially infectious porcine microorganisms, though perhaps not all, can be eradicated from the donor herd by careful husbandry techniques, such as early weaning and barrier housing. ${ }^{93,94}$ The potential risks of xenotransplantation in this respect are therefore considered to be low. ${ }^{95}$

However, the presence of porcine endogenous retroviruses (PERV) in the genome of all pig cells has caused concern. ${ }^{96}$ Although human cells include similar endogenous retroviruses that do not appear to cause humans significant health problems, the issue has been raised about the potential transfer of PERV into human hosts, with possible recombination of porcine and human retroviruses to form new viruses. However, to date there has been no evidence of transmission of PERV into humans or nonhuman primates following porcine organ, tissue, or cell xenotransplantation procedures. ${ }^{93,96}$ It is now thought unlikely that these viruses will be problematic. Furthermore, if the actual risk proves to be greater than presently thought, genetic engineering techniques are available to inhibit activation of porcine endogenous retroviruses. ${ }^{97,98}$

\section{Regulation of clinical xenotransplantation}

It is unlikely that national and international regulatory authorities, such as the Food and Drug Administration in the USA, will prohibit clinical xenotransplantation on the basis of the potential risk of infection alone, though they will insist on careful monitoring of the organ-source animals and of the human recipients for many years following the transplant procedure. ${ }^{91,99,100}$

Table 7 Predicted order of clinical trials of pig organ/cell transplantation

I. Cornea (corneal blindness)

2. Pancreatic islets (type I diabetes)

3. Neuronal (dopamine-producing) cells (Parkinson's disease)

4. Livers (initially as a bridge)

5. Hearts (initially as a bridge)

6. Kidneys

7. Lungs

8. Red blood cells
It should be borne in mind that in comparison with the transplantation of human organs from donors who have been identified only within the previous few hours and in whom monitoring for all infectious agents is not possible during this very short period of time, clinical xenotransplantation is likely to be a safer procedure. If consistent successful function of a pig organ or cell transplant in a nonhuman primate recipient can be obtained, it is likely that clinical trials will be equally successful.

\section{Conclusion}

Within the next few years, further clinical trials of xenotransplantation will almost certainly be undertaken. The likely sequence of clinical trials is outlined in Table 7. Initially, these may involve transplantation of corneas, islets, and neuronal cells. During this period, as new improved genetically engineered pigs become available, we predict it will become justified to carry out organ xenotransplants as bridges to allotransplantation, eg, involving the liver or heart. Finally, organ xenotransplantation will be carried out as a definitive procedure, anticipating relatively long-term graft survival. Even if the survival of the graft is not as long as that of an allograft, the limitless availability of organsource pigs will enable retransplantation to be carried out whenever indicated.

It should be remembered that allotransplantation, which really began in the early $1950 \mathrm{~s}$, has taken 60 years to reach its present state of success, even though problems remain, particularly with regard to long-term graft survival (chronic rejection) and the complications of long-term immunosuppressive therapy. The goal of inducing a state of immunological tolerance to the graft has been elusive, but may be easier to achieve in xenotransplantation where the donor can be identified and the timing of any pretreatment and the operative procedure planned well in advance.

It is exceedingly unlikely that clinical xenotransplantation will be successful overnight. There will be a distinct learning curve, with steady improvement in results over many years, in part relating to the availability of 'better' pigs with more advanced genetic manipulations, before pig cells and organs can routinely replace human cells and organs for these lifesaving procedures. Nevertheless, we predict that eventually allotransplantation will become of historical interest only.

\section{Acknowledgments}

Work on xenotransplantation in the Thomas E Starzl Transplantation Institute of the University of Pittsburgh is supported in part by NIH grants \#U19 AI090959-01, 
\#U01 AI068642, and \#R21 A1074844, and by sponsored research agreements between the University of Pittsburgh and Revivicor, Blacksburg, VA.

\section{Disclosure}

David Ayares is an employee of Revivicor, Blacksburg, VA, USA.

\section{References}

1. Cooper DKC, Lanza RP. Xeno - The Promise of Transplanting Animal Organs into Humans. New York: Oxford University Press; 2000: $1-274$.

2. Cooper DKC, Gollackner B, Sachs DH. Will the pig solve the transplantation backlog? Аппи Rev Med. 2002;53(1):133-147.

3. Ekser B, Ezzelarab M, Hara H, et al. Clinical xenotransplantation - the next medical revolution? Lancet. 2012;379(9816):672-683.

4. Deschamps JY, Roux FA, Sai P, Gouin E. History of xenotransplantation. Xenotransplantation. 2005;12(2):91-109.

5. Hara H, Cooper DKC. Xenotransplantation - the future of corneal transplantation? Cornea. 2011;30(4):371-378.

6. Reemtsma K, McCracken BH, Schlegel JU, et al. Renal heterotransplantation in man. Ann Surg. 1964;160(3):384-410.

7. Groth CG, Korsgren O, Tibell A, et al. Transplantation of porcine fetal pancreas to diabetic patients. Lancet. 1994;344(8934): 1402-1404.

8. Galili U, Shohet SB, Kobrin E, Stults CL, Macher BA. Man, apes, and Old World monkeys differ from other mammals in the expression of alpha-galactosyl epitopes on nucleated cells. J Biol Chem. 1988;263(33):17755-17762.

9. Good AH, Cooper DKC, Malcolm AJ, et al. Identification of carbohydrate structures that bind human antiporcine antibodies: implications for discordant xenografting in man. Transplant Proc. 1992;24(2):559-562.

10. Oriol R, Ye Y, Koren E, Cooper DKC. Carbohydrate antigens of pig tissues reacting with human natural antibodies as potential targets for hyperacute vascular rejection in pig-to-man organ xenotransplantation. Transplantation. 1993;56(6):1433-1442.

11. Rose AG, Cooper DKC, Human PA, Reichenspurner H, Reichart B. Histopathology of hyperacute rejection of the heart - experimental and clinical observation in allografts and xenografts. $J$ Heart Transplant. 1991;10(2):223-234.

12. Rose AG, Cooper DKC. Venular thrombosis is the key event in the pathogenesis of antibody-mediated cardiac rejection. Xenotransplantation. 2000;7(1):31-41.

13. Ezzelarab M, Garcia B, Azimzadeh A, et al. The innate immune response and activation of coagulation in $\alpha 1,3$-galactosyltransferase gene-knockout xenograft recipients. Transplantation. 2009;87(6):805-812.

14. Cooper DKC, Koren E, Oriol R. Genetically engineered pigs. Lancet. 1993;342(8872):682-683.

15. Phelps CJ, Koike C, Vaught TD, et al. Production of $\alpha 1,3-$ galactosyltransferase-deficient pigs. Science. 2003;299(5605): 411-414.

16. Kolber-Simonds D, Lai L, Watt SR, et al. Production of $\alpha 1$, 3-galactosyltransferase null pigs via nuclear transfer with fibroblasts bearing loss of heterozygosity mutations. Proc Natl Acad Sci U S A. 2004;101(19):7335-7340.

17. Dalmasso AP, Vercellotti GM, Platt JL, Bach FH. Inhibition of complement-mediated endothelial cell cytotoxicity by decayaccelerating factor. Potential for prevention of xenograft hyperacute rejection. Transplantation. 1991;52(3):530-533.

18. White DJ, Oglesby T, Liszewski MK, et al. Expression of human decay accelerating factor or membrane cofactor protein genes on mouse cells inhibits lysis by human complement. Transpl Int. 1992;5(Suppl 1): $648-650$.
19. Cozzi E, White DJG. The generation of transgenic pigs as potential organ donors for humans. Nat Med. 1995;1(9):964-969.

20. Loveland BE, Milland J, Kyriakou P, et al. Characterization of a CD46 transgenic pig and protection of transgenic kidneys against hyperacute rejection in non-immunosuppressed baboons. Xenotransplantation. 2004;11(2):171-183.

21. Hara $\mathrm{H}$, Long $\mathrm{C}$, Lin $\mathrm{YJ}$, et al. In vitro investigation of pig cells for resistance to human antibody-mediated rejection. Transpl Int. 2008; 21(12):1163-1174.

22. Rood PP, Hara H, Busch JL, et al. Incidence and cytotoxicity of antibodies in cynomolgus monkeys directed to nonGal antigens, and their relevance for experimental models. Transpl Int. 2006;19(2): $158-165$.

23. Rood PP, Tai HC, Hara H, et al. Late onset of development of natural anti-nonGal antibodies in infant humans and baboons: implications for xenotransplantation in infants. Transpl Int. 2007;20(12):1050-1058.

24. Yeh P, Ezzelarab M, Bovin N, et al. Investigation of potential carbohydrate antigen targets for human and baboon antibodies. Xenotransplantation. 2010;17(3):197-206.

25. Buhler L, Awwad M, Basker M, et al. High-dose porcine hematopoietic cell transplantation combined with CD40 ligand blockade in baboons prevents an induced anti-pig humoral response. Transplantation. 2000;69(11):2296-2304.

26. Cozzi E, Vial C, Ostlie D, et al. Maintenance triple immunosuppression with cyclosporin A, mycophenolate sodium and steroids allows prolonged survival of primate recipients of $\mathrm{hDAF}$ porcine renal xenografts. Xenotransplantation. 2003;10(4):300-310.

27. McGregor CG, Davies WR, Oi K, et al. Cardiac xenotransplantation: recent preclinical progress with 3-month median survival. $J$ Thorac Cardiovasc Surg. 2005;130(3):844-851.

28. Kuwaki K, Tseng YL, Dor FJ, et al. Heart transplantation in baboons using $\alpha 1,3$-galactosyltransferase gene-knockout pigs as donors: initial experience. Nat Med. 2005;11(1):29-31.

29. Yamada K, Yazawa K, Shimizu A, et al. Marked prolongation of porcine renal xenograft survival in baboons through the use of $\alpha 1,3$-galactosyltransferase gene-knockout donors and the cotransplantation of vascularized thymic tissue. Nat Med. 2005;11(1):32-34.

30. Houser SL, Kuwaki K, Knosalla C, et al. Thrombotic microangiopathy and graft arteriopathy in pig hearts following transplantation into baboons. Xenotransplantation. 2004;11(5):416-425.

31. Kuwaki K, Knosalla C, Dor FJ, et al. Suppression of natural and elicited antibodies in pig-to-baboon heart transplantation using a human antiCD154 monoclonal antibody-based regimen. Am J Transplant. 2004; 4(3):363-372.

32. Bühler L, Basker M, Alwayn IP, et al. Coagulation and thrombotic disorders associated with pig organ and hematopoietic cell transplantation in nonhuman primates. Transplantation. 2000;70(9): $1323-1331$

33. Cowan PJ, Aminian A, Barlow H, et al. Renal xenografts from triple-transgenic pigs are not hyperacutely rejected but cause coagulopathy in non-immunosuppressed baboons. Transplantation. 2000;69(12):2504-2515.

34. Lin CC, Ezzelarab M, Shapiro R, et al. Tissue factor expression on recipient platelets is associated with consumptive coagulopathy in pigto-primate kidney xenotransplantation. Am J Transplant. 2010;10(7): 1556-1568

35. Bach FH, Robson SC, Ferran C, et al. Endothelial cell activation and thromboregulation during xenograft rejection. Immunol Rev. 1994; 141(1):5-303.

36. Robson SC, Cooper DKC, d'Apice AJF. Disordered regulation of coagulation and platelet activation in xenotransplantation. Xenotransplantation. 2000;7(3):166-176.

37. Schulte am Esch J 2nd, Rogiers X, Robson SC. Molecular incompatibilities in hemostasis between swine and men - impact on xenografting. Ann Transplant. 2001;6(3):12-16.

38. Cowan PJ. Coagulation and the xenograft endothelium. Xenotransplantation. 2007;14(1):7-12. 
39. Cowan PJ, Roussell JC, d'Apice AJF. The vascular and coagulation issues in xenotransplantation. Curr Opin Organ Transplant. 2009;14(2): 161-167.

40. Schmelzle M, Schulte am Esch J 2nd, Robson SC. Coagulation, platelet activation and thrombosis in xenotransplantation. Curr Opin Organ Transplant. 2010;15(2):212-218.

41. Knosalla C, Yazawa K, Behdad A, et al. Renal and cardiac endothelial heterogeneity impact acute vascular rejection in pig-to-baboon xenotransplantation. Am J Transplant. 2009;9(5):1006-1016.

42. Mohiuddin MM, Corcoran PC, Singh AK, et al. B-cell depletion extends the survival of GTKO.hCD46Tg pig heart xenografts in baboons for up to 8 months. Am J Transplant. 2012;12(3):763-771.

43. Vial CM, Ostlie DJ, Bhatti FN, et al. Life supporting function for over one month of a transgenic porcine heart in a baboon. J Heart Lung Transplant. 2000;19(2):224-229.

44. McGregor C. Xenogeneic orthotopic heart transplantation: Where are we now? [abstract]. Xenotransplantation. 2010;17:114.

45. Ramirez P, Chavez R, Majado M, et al. Life-supporting human complement regulator decay accelerating factor transgenic pig liver xenograft maintains the metabolic function and coagulation in the nonhuman primate for up to 8 days. Transplantation. 2000;70(7):989-998.

46. Ekser B, Echeverri GJ, Cortese Hassett A, et al. Hepatic function after genetically engineered pig liver transplantation in baboons. Transplantation. 2010;90(5):483-493.

47. Ekser B, Long C, Echeverri GJ, et al. Impact of thrombocytopenia on survival of baboons with genetically modified pig liver transplants: clinical relevance. Am J Transplant. 2010;10(2):273-285.

48. Burlak C, Paris LL, Chihara RK, et al. The fate of human platelets perfused through the pig liver: implications for xenotransplantation. Xenotransplantation. 2010;17(5):350-361.

49. Ezzelarab M, Ekser B, Gridelli B, Iwase H, Ayares D, Cooper DKC. Thrombocytopenia after pig-to-baboon liver xenotransplantation: where do platelets go? Xenotransplantation. 2011;18(6):320-327.

50. Nguyen BN, Azimzadeh AM, Zhang T, et al. Life-supporting function of genetically modified swine lungs in baboons. J Thorac Cardiovasc Surg. 2007;133(5):1354-1363.

51. Cantu E, Balsara KR, Li B, et al. Prolonged function of macrophage, von Willibrand factor-deficient porcine pulmonary xenografts. Am J Transplant. 2007;7(1):66-75.

52. Cooper DKC, Ekser B, Burlak C, et al. Clinical lung xenotransplantationwhat genetic modifications to the organ-source pig may be necessary? Xenotransplantation. 2012. In press.

53. Ezzelarab M, Ekser B, Isse K, et al. Elevated C-reactive protein and IL-6 levels precede consumptive coagulopathy in GTKO pig organ xenograft recipients [abstract]. Xenotransplantation. 2011;18:287.

54. Bennet W, Sundberg B, Lundgren T, et al. Damage to porcine islets of Langerhans after exposure to human blood in vitro, or after intraportal transplantation to cynomologus monkeys: protective effects of sCR1 and heparin. Transplantation. 2000;69(5):711-719.

55. Moberg L, Johansson H, Lukinius A, et al. Production of tissue factor by pancreatic islet cells as a trigger of detrimental thrombotic reactions in clinical islet transplantation. Lancet. 2002;360(9350):2039-2045.

56. Ozmen L, Ekdahl KN, Elgue G, Larsson R, Korsgren O, Nilsson B. Inhibition of thrombin abrogates the instant blood-mediated inflammatory reaction triggered by isolated human islets: possible application of the thrombin inhibitor melagatran in clinical islet transplantation. Diabetes. 2002;51(6):1779-1784.

57. Johansson H, Lukinius A, Moberg L, et al. Tissue factor produced by the endocrine cells of the islets of Langerhans is associated with a negative outcome of clinical islet transplantation. Diabetes. 2005; 54(6):1755-1762.

58. Goto M, Tjernberg J, Dufrane D, et al. Dissecting the instant blood-mediated inflammatory reaction in islet xenotransplantation. Xenotransplantation. 2008;15(4):225-234.

59. Ji M, Yi S, Smith-Hurst H, et al. The importance of tissue factor expression by porcine NICC in triggering IBMIR in the xenograft setting. Transplantation. 2011;91(8):841-846.
60. van der Windt DJ, Bottino R, Casu A, et al. Rapid loss of intraportally transplanted islets: an overview of pathophysiology and preventive strategies. Xenotransplantation. 2007;14(4):288-297.

61. van der Windt DJ, Marigliano M, Jing H, et al. Pathophysiological events after exposure of isolated pancreatic islets to blood. Cell Transplant. 2012. In press.

62. Cardona K, Korbutt GS, Milas Z, et al. Long-term survival of neonatal porcine islets in nonhuman primates by targeting costimulation pathways. Nat Med. 2006;12(3):304-306

63. Hering BJ, Cooper DKC, Cozzi E, et al. The International Xenotransplantation Association consensus statement on conditions for undertaking clinical trials of porcine islet products in type 1 diabetes executive summary. Xenotransplantation. 2009;16(4):196-202.

64. van der Windt DJ, Bottino R, Casu A, et al. Long-term controlled normoglycemia in diabetic non-human primates after transplantation with hCD46 transgenic porcine islets. Am J Transplant. 2009;9(12): 2716-2726.

65. Rayat GR, Rajotte RV, Korbutt GS. Potential application of neonatal porcine islets as treatment for type 1 diabetes: a review. Ann NY Acad Sci. 1999;18(2):175-188.

66. Emamaullee JA, Shapiro AM, Rajotte RV, Korbutt G, Elliott JF. Neonatal porcine islets exhibit natural resistance to hypoxia-induced apoptosis. Transplantation. 2006;82(7):945-952.

67. van der Windt DJ, Echeverri G, Cooper DKC. The choice of anatomical site for islet transplantation. Cell Transplant. 2008;17(9):1005-1014.

68. Elliott RB, Escobar L, Tan PL, et al. Live encapsulated porcine islets from a type 1 diabetic patient $9.5 \mathrm{yr}$ after xenotransplantation. Xenotransplantation. 2007;14(2):157-161.

69. Dufrane D, Goebbels RM, Gianello P. Alginate macroencapsulation of pig islets allows correction of streptozotocin-induced diabetes in primates up to 6 months without immunosuppression. Transplantation. 2010;90(10):1054-1062.

70. Elliott RB. Towards xenotransplantation of pig islets in the clinic. Curr Opin Organ Transplant. 2011;16(2):195-200.

71. Badin RA, Padoan A, Vadori M, et al. Porcine embryonic xenografts transgenic for CTLA4-Ig enable longterm recovery in Parkinsonian macaques [abstract]. Am J Transplant. 2010;10(6 Suppl 4):208.

72. Pan Z, Sun C, Jie Y, Wang N, Wang L. WZS-pig is a potential donor alternative in corneal xenotransplantation. Xenotransplantation. 2007; 14(6):603-611.

73. Kim MK, Wee WR, Park CG, Kim SJ. Xenocorneal transplantation. Curr Opin Organ Transplant. 2011;16(2):231-236.

74. Zhu A. Introduction to porcine red cells: implications for xenotransplantation. Semin Hematol. 2000;37(2):143-149.

75. Cooper DKC, Hara H, Yazer M. Genetically engineered pigs as a source for clinical red blood cell transfusion. Clin Lab Med. 2010;30(2):365-380.

76. Bouhours D, Pourcel C, Bouhours JF. Simultaneous expression by porcine aorta endothelial cells of glycosphingolipids bearing the major epitope for human xenoreactive antibodies (Gal $\alpha 1-3 \mathrm{Gal})$, blood group $\mathrm{H}$ determinant and N-glycolylneuraminic acid. Glycoconjugate J. 1996;13(6):947-953.

77. Zhu A, Hurst R. Anti-N-glycolylneuraminic acid antibodies identified in healthy human serum. Xenotransplantation. 2002;9(6):376-381.

78. Miwa Y, Kobayashi T, Nagasaka T, et al. Are N-glycolylneuraminic acid (Hanganutziu-Deicher) antigens important in pig-to-human xenotransplantation? Xenotransplantation. 2004;11(3):247-253.

79. Padler-Karavani V, Varki A. Potential impact of the non-human sialic acid N-glycolylneuraminic acid on transplant rejection risk. Xenotransplantation. 2011;18(1):1-5

80. Cooper DKC, Tseng YL, Saidman SL. Allo- and xeno-antibody crossreactivity in transplantation. Transplantation. 2004;77(1):1-5.

81. Hammer C. Evolutionary, physiological, and immunological considerations in defining a suitable donor for man. In: Cooper DKC, Kemp E, Reemtsma K, White DJC, editors. Xenotransplantation: The Transplantation of Organs and Tissues between Species. Heidelberg: Springer; 1991:429-438. 
82. Soin B, Smith KG, Zaidi A, et al. Physiological aspects of pig-to-primate renal xenotransplantation. Kidney Int. 2001;60(4):1592-1597.

83. Ibrahim Z, Busch J, Awwad M, et al. Selected physiologic compatibilities and incompatibilities between human and porcine organ systems. Xenotransplantation. 2006;13(6):488-499.

84. Casu A, Bottino R, Balamurugan AN, et al. Metabolic aspects of pigto-monkey (Macaca fascicularis) islet transplantation: implications for translation into clinical practice. Diabetologia. 2008;51(1):120-129.

85. Cooper DKC, Keogh A, Brink J, et al. Report of the Xenotransplantation Advisory Committee of the International Society for Heart and Lung Transplantation: the present status of xenotransplantation and its potential role in the treatment of end-stage cardiac and pulmonary diseases. J Heart Lung Transplant. 2000;19(12):1125-1165.

86. Cooper DKC, Casu A. The International Xenotransplantation Association consensus statement on conditions for undertaking clinical trials of porcine islet products in type 1 diabetes - Chapter 4: Pre-clinical efficacy and complication data required to justify a clinical trial. Xenotransplantation. 2009;16(4):229-238.

87. O'Connell PJ. The International Xenotransplantation Association consensus statement on conditions for undertaking clinical trials of porcine islet products in type 1 diabetes - Chapter 6: Patient selection for pilot clinical trials of islet xenotransplantation. Xenotransplantation. 2009;16(4):249-254.

88. World Health Organization. First WHO Global Consultation on Regulatory Requirements for Xenotransplantation Clinical Trials; November 19-21, 2008; Changsha, China. The Changsha Communiqué. Xenotransplantation. 2009;16(4):58-60.

89. Sykes M, d'Apice A, Sandrin M. IXA Ethics Committee. Position paper of the Ethics Committee of the International Xenotransplantation Association. Transplantation. 2004;78(8):1101-1107.

90. Vanderpool HY. The International Xenotransplantation Association consensus statement on conditions for undertaking clinical trials of porcine islet products in type 1 diabetes - Chapter 7: Informed consent and xenotransplantation clinical trials. Xenotransplantation. 2009;16(4):255-262.
91. Cozzi E, Tallacchini M, Flanagan EB, Pierson RN 3rd, Sykes M, Vanderpool HY. The International Xenotransplantation Association consensus statement on conditions for undertaking clinical trials of porcine islet products in type 1 diabetes - Chapter 1: Key ethical requirements and progress toward the definition of an international regulatory framework. Xenotransplantation. 2009;16(4):203-214.

92. Ekser B, Gridelli B, Tector AJ, et al. Pig liver xenotransplantation as a bridge to allotransplantation in acute liver failure: which patients might benefit? Transplantation. 2009;88(9):1041-1049.

93. Onions D, Cooper DKC, Alexander TJL, et al. An assessment of the risk of xenozoonotic disease in pig-to-human xenotransplantation. Xenotransplantation. 2000;7(2):143-155.

94. Mueller NJ, Kuwaki K, Knosalla C, et al. Early weaning of piglets fails to exclude porcine lymphotropic herpesvirus. Xenotransplantation. 2005;12(1):59-62.

95. Fishman JA, Patience C. Xenotransplantation: infectious risk revisited. Am J Transplant. 2004;4(9):1383-1390.

96. Denner J, Schuurman HJ, Patience C. The International Xenotransplantation Association consensus statement on conditions for undertaking clinical trials of porcine islet products in type 1 diabetes - Chapter 5: Strategies to prevent transmission of porcine endogenous retroviruses. Xenotransplantation. 2009;16(4):239-248.

97. Dieckhoff B, Petersen B, Kues WA, Kurth R, Niemann H, Denner J. Knockdown of porcine endogenous retrovirus (PERV) expression by PERV-specific shRNA in transgenic pigs. Xenotransplantation. 2008;15(1):36-45.

98. Ramsoondar J, Vaught T, Ball S, et al. Production of transgenic pigs that express porcine endogenous retrovirus small interfering RNAs Xenotransplantation. 2009;16(4):164-180.

99. Tibell A, Lundgren T. Xenotransplantation - clinical activities and regulatory development. Acta Vet Scand Suppl. 2004;99:19-23.

100. Schuurman HJ. Regulatory aspects of pig-to-human islet transplantation. Xenotransplantation. 2008;15(2):116-120.

101. Taniguchi S, Cooper DKC. Clinical xenotransplantation: past, present and future. Ann R Coll Surg Engl. 1997;79(1):13-19.
Transplant Research and Risk Management

\section{Publish your work in this journal}

Transplant Research and Risk Management is an international, peerreviewed open access journal focusing on all aspects of transplantation and risk management to achieve optimal outcomes in the recipient improving survival and quality of life. The journal welcomes submitted papers covering original research, basic science, clinical studies,

\section{Dovepress}

reviews \& evaluations, guidelines, expert opinion and commentary, case reports and extended reports. The manuscript management system is completely online and includes a very quick and fair peer-review system, which is all easy to use. Visit http://www.dovepress.com/ testimonials.php to read real quotes from published authors. 